\title{
PRODUÇÃO DO PLANO DE EDUCAÇÃO PERMANENTE EM SAÚDE: RELATO DE EXPERIÊNCIA NO OESTE CATARINENSE
}

\author{
Carine Vendruscolo ${ }^{1}$, Denise Zocche ${ }^{2}$, Altamir Trevisan Dutra ${ }^{3}$
}

${ }^{1}$ Enfermeira. Doutora em Enfermagem, Docente do Departamento de Enfermagem da Universidade do Estado de Santa Catarina. Chapecó, SC, Brasil.

${ }^{2}$ Enfermeira. Doutora em Enfermagem. Docente do Departamento de Enfermagem da Universidade do Estado de Santa Catarina. Chapecó, SC, Brasil.

${ }^{3}$ Educador Físico. Doutor em Saúde Coletiva. Docente da Área de Ciências da Saúde da Universidade Comunitária da Região de Chapecó (Unochapeco), Chapecó, SC, Brasil.

RESUMO: Relato da experiência de elaboração do Plano de Ações Regionais de Educação Permanente em Saúde na macrorregião oeste do estado de Santa Catarina em 2014, mediante o olhar dos representantes dos gestores da saúde e da educação, dos trabalhadores da saúde, das instituições formadoras e do controle social - quadrilátero da formação. A oficina contou com a representação dos 26 municípios da região, tendo representados os segmentos que compõem a Comissão de Integração Ensino Serviço. Após concluídos os trabalhos de grupos, todos se reuniram em plenária para aprovação das propostas que emergiram. Destacou-se a pouca representatividade do controle social em cada um dos municípios, a presença de Secretários Municipais da Educação e a participação da categoria profissional enfermagem, representando as instituições formadoras. A experiência confirmou os pressupostos do quadrilátero e as discussões geraram oportunidades significativas de encontros, traduzindo a complexidade, a riqueza e a potência dos movimentos de Educação Permanente.

DESCRITORES: Educação continuada; Gestão em saúde; Formação de recursos humanos; Políticas públicas.

\section{PRODUCTION OF THE PLAN FOR CONTINUING HEALTHEDUCATION: REPORT OF AN EXPERIENCE IN THE WESTERN REGION OF THE STATE OF SANTA CATARINA}

ABSTRACT: Report of the experience of elaboration of the Plano de Ações Regionais de Educação Permanente em Saúde (Regional action plan for continuing health education) in the western macro-region of the state of Santa Catarina, in 2014, by representatives of health and education managers, health workers, educational institutions and social control - the four elements (quadrilateral) of training. Twenty-six (26) cities of the region participated in the workshop, being represented by the segments that compose the Comissão de Integração Ensino Serviço - CIES (Commission for integrating teaching and service). After the end of the activities of the groups, the participants gathered in a plenary meeting for the approval of the proposals submitted. It should be stressed the scarce representativeness of social control in each of the cities, the presence of municipal secretaries of education and the participation ofthe nursing profession, representing the educational institutions. The experience corroborated the assumptions of the quadrilateral, and the discussions provided significant opportunities for new meetings, translating the complexity, the wealth and the power of Continuing Education movements.

DESCRIPTORS: Continuing education; Health management; Human Resources Training; Public policies.

\section{PRODUCCIÓN DEL PLAN DE EDUCACIÓN PERMANENTE EN SALUD: RELATO DE EXPERIENCIA EN OESTE DE SANTA CATARINA}

RESUMO: Relato de experiencia de elaboración del Plan de Acciones Regionales de Educación Permanente en Salud en la macrorregión oeste del estado de Santa Catarina en 2014, considerando la visión de los representantes de los gestores de la salud y de la educación, de los trabajadores de salud, de las instituciones formadoras y del control social - cuadrilátero de la formación. El evento contó con la representación de los 26 municipios de la región, siendo representados los segmentos que componen la Comisión de Integración Enseñanza Servicio. Después de concluidos los trabajos de grupos, todos se reunieron para aprobación de las propuestas resultantes. Se ha destacado la poca representatividad del control social en cada uno de los municipios, la presencia de Secretarios Municipales de la Educación y la participación de la categoría profesional de enfermería, representando las instituciones formadoras. La experiencia confirmó los presupuestos de cuadrilátero y las discusiones generaron oportunidades significativas de encuentros, traduciendo la complejidad, la riqueza y la potencia de los movimientos de Educación Permanente. DESCRITORES: Educación continuada; Gestión en salud; Formación de recursos humanos; Políticas públicas. 


\section{INTRODUÇÃO}

A Educação Permanente em Saúde (EPS) segue os pressupostos pedagógicos formulados pela Organização Panamericana de Saúde e Organização Mundial da Saúde (OPAS/ OMS), na década de 1980, na direção de uma aprendizagem significativa, que pressupõe abordar questões expressivas para os sujeitos, ativamente envolvidos e protagonistas em tempo integral. Assim, a EPS propõe reordenar práticas, promovendo mudanças no processo cotidiano de trabalho das equipes de saúde, com base nos nós críticos do dia a dia, a partir das necessidades específicas dos trabalhadores, estando apoiada no princípio pedagógico crítico, problematizador e reflexivo ${ }^{(1)}$.

Os Colegiados de Gestão Regional (CGR), nominados a partir do Decreto 7508/2011 de Comissões Intergestores Regionais $(\mathrm{CIR})^{(2)}$, por meio das Comissões Permanentes de Integração Ensino-Serviço (CIES), instâncias previstas na Portaria 1.996/07 que regulamenta a Política Nacional de Educação Permanente em Saúde (PNEPS), participam da formulação, execução, acompanhamento e avaliação de ações da EPS. As CIES deverão ser compostas pelos gestores de saúde, gestores de educação, trabalhadores do Sistema Único de Saúde (SUS), instituições de ensino com cursos na área da saúde e movimentos sociais ligados à gestão das políticas públicas de saúde e do controle social no SUS ${ }^{(3)}$.

Nesse contexto, as demandas de ações de educação permanente apresentadas pelos 26 municípios que compõe a CIR e a CIES da macrorregião oeste de Santa Catarina são organizadas, conforme previsto no Anexo II da Portaria no 1.996/07, por meio da elaboração de um Plano de Ações Regionais para Educação Permanente em Saúde (PAREPS) que, nesta macrorregião, foi concluído em 2008 e revisado em 2010. Após esse período, poucas das atividades propostas foram operacionalizadas.

Contudo, a CIES Oeste vem participando ativamente, com alguns dos seus integrantes, em intervenções estaduais, a fim de implementar ações propostas no Plano Estadual de EPS. Uma dessas ações, o Encontro Estadual, envolveu as 16 regiões de saúde, no ano de 2014, fomentou a realização da III Oficina para Elaboração do PAREPS na macrorregião oeste. Nessa Oficina, atendendo a Política, o PAREPS de 2010 foi retomado e reformulado, mediante a análise das necessidades de formação dos trabalhadores do SUS e do território.
Compreende-se o reconhecimento do território como uma primeira etapa desse processo de planejamento. Nesse sentido, a caracterização da população e de suas necessidades de saúde passa pela compreensão de que saúde envolve mais do que ausência de doença. Queremos dizer que, para dar sentido às ações de educação permanente, é preciso reconhecer que o "andar da vida" dos usuários, implica e influencia os processos de adoecimento e de saúde. Além disso, pensar as necessidades de educação permanente para determinado território implica também em reconhecer que a reorientação dos sistemas de saúde segue na direção de afirmar-se como "espaço da saúde", e não exclusivamente da atenção à doença. Essa construção social precisa estar ancorada na concepção do processo saúdedoença e no reconhecimento das necessidades de saúde individuais, para além das demandas programáticas associadas ao ciclo vital(4).

O presente relato objetiva descrever a experiência de elaboração do PAREPS nesse território, mediante o olhar dos representantes dos gestores da saúde e da educação, dos trabalhadores do SUS, das instituições formadoras e do controle social - quadrilátero da formação que compõem a macrorregião oeste de saúde do estado de Santa Catarina.

O conceito de "quadrilátero" dependerá da qualidade da formação, da qual resulta a atenção a critérios de relevância para o desenvolvimento tecnoprofissional e para o ordenamento da rede de atenção. "Cada face [do quadrilátero] comporta uma convocação pedagógica, uma imagem de futuro, uma luta política e uma trama de conexões. Cada interseção traz como consequência trajetos formativos postos em ato" (5:47-48).

\section{MÉTODO}

A III Oficina de elaboração do PAREPS 2015/2016 contou com a representação dos 26 municípios da macrorregião oeste, sendo um de cada segmento que compõe a CIES - gestão, atenção, ensino e controle social. Da grande roda de debates, fizeram parte, portanto, 34 sujeitos: cinco representando o segmento ensino, oriundos das Instituições de Ensino Superior (IES) da região; 12 representando o segmento gestão em saúde, na sua maioria Secretários Municipais de Saúde membros da CIR e outros, Secretários Municipais da Educação; três representando o controle social e 14 representando os trabalhadores do SUS ou o segmento atenção em saúde.

O planejamento da Oficina foi conduzido 
pela "Câmara Técnica da CIES", composta por representantes das IES, um membro da CIR, um representante da Gerência Regional de Saúde da Secretaria de Estado do Desenvolvimento Regional do município de Chapecó, representantes do Hospital Regional do Oeste e membro da Associação de Municípios do Oeste de Santa Catarina (AMOSC). A partir de alguns encontros presenciais e outras trocas virtuais, planejou-se uma atividade de grupos, divididos de acordo com os segmentos, norteada por roteiros de proposição de ações de EPS que representassem uma ou mais demandas daquele segmento, em nível regional.

Inicialmente, abordou-se conceitualmente a PNEPS e os segmentos organizaram-se em três grupos. Estes trabalharam sob tutoria dos representantes da Câmara Técnica no sentido de fomentar e sistematizar as reflexões a partir da identificação das demandas de cada região. Destaca-se que o segmento controle social, por ter menor representatividade, organizou-se juntamente com o segmento ensino. A dinâmica utilizada pelos grupos foi a roda de conversa, guiada por um roteiro que continha os elementos: ação, objetivo, sujeitos envolvidos, responsáveis, local, previsão temporal, custos e proposta de avaliação. Os grupos trabalharam em torno de duas horas na elaboração das propostas, havendo um moderador e um relator para explanação posterior na plenária.

Após concluídos os planos nos grupos, todos se reuniram em plenária para proposição, defesa e aprovação das nove propostas que emergiram.

\section{RESULTADOS}

O segmento gestão apresentou três propostas: capacitação em redes, mostra regional da atenção básica, e curso de aperfeiçoamento para coordenadores e gestores; o segmento atenção apresentou quatro propostas: capacitação em rede de urgência e emergência, introdutório para equipes da Estratégia Saúde da Família, pós-graduação em gestão, e gerenciamento e cuidando do trabalhador; e os segmentos controle social e ensino apresentaram duas propostas: capacitação para conselheiros, e fórum sobre saúde e educação. As propostas foram discutidas entre os participantes, sendo consideradas as mais emergentes o curso introdutório - uma nova edição, tratando inclusive do Núcleo de Apoio à Saúde da Família (NASF) - e um fórum de discussão sobre saúde e educação, na perspectiva do conceito ampliado de saúde e do papel dos diferentes setores. O fórum teria como público alvo, entre outros, os próprios componentes da CIES.

Ao final da oficina, a Câmara Técnica da CIES reorganizou as propostas segundo afinidade dos membros, para elaborar e discutir os projetos a serem, posteriormente, executados com recursos advindos do governo federal para a CIES, com a contrapartida das Secretarias Municipais de Saúde e/ou Educação e das IES envolvidas.

\section{DISCUSSÃO}

Destaca-se nessa experiência a pouca participação e representatividade do controle social de cada um dos municípios, representados pelos membros dos respectivos Conselhos Municipais de Saúde. A participação dos usuários em instâncias de decisão na área da saúde é um direito garantido por lei no Brasil, mediante ação denominada de controle social, exercida em especial nos conselhos gestores ${ }^{(6)}$.

O usuário do SUS é o cidadão que faz uso, efetivamente, do serviço. Isso significa que, em tese, qualquer representante de qualquer um dos lados do quadrilátero poderia ser duplo representante, o que todavia, para garantir e respeitar o princípio doutrinário da lei, deveria ser evitado. Outros estudos ${ }^{(7)}$ realizados nesse território revelam que em instâncias de gestão de alguns processos de educação em saúde, via de regra, a participação do controle social é pouco frequente e, quando ocorre, nem sempre o representante é o usuário (no sentido desejado) do serviço, mas sim outro membro do Conselho Municipal de Saúde (muito frequentemente, profissionais de saúdeou representantedagestão). O próprio Conselho, por conta da paridade, é composto por usuários, prestadores de serviço, trabalhadores ou gestores, o que compromete a composição do quadrilátero, por si só. Sendo assim, esse "quadrilátero", por vezes, não se afirma como tal, pois ora faltam elementos para encaixar os vértices, ora percebe-se a intervenção de outros elementos em um mesmo segmento, configurando-se o que podemos definir como um prisma, para além de um quadrilátero.

Inicialmente, a experiência confirmou os pressupostos do quadrilátero, mas, para além disso, as discussões nos grupos geraram oportunidades significativas de encontros que traduziram-se em prismas, os quais elucidam melhor a complexidade, a riqueza e a potência dos movimentos de EPS. Exemplo disso foi a presença de gestores das Secretarias Municipais 
de Educação, que não está prevista em atividades dessa natureza, mas que contribuiu, sobremaneira, para a determinação das necessidades de EPS.

Cumpre destacar que as três IES estavam representadas por docentes e discentes de uma categoria profissional, enfermagem, o que pode ter relação com o marcante envolvimento dessa profissão com os processos de gestão e educação em saúde. Aliás, o número de sujeitos no segmento ensino, bem como o efetivo envolvimento destes no movimento, faz refletir sobre a necessidade de integração entre as áreas da educação e da saúde em nível regional, cuja dificuldade, no sentido dialógico e de reconhecimento e compreensão dos diferentes pontos de vista e necessidades, é observada em outros estudos, no território ${ }^{(7-8)}$.

\section{CONSIDERAÇÕES FINAIS}

O PAREPS 2014 deverá orientar as ações nos próximos dois anos na macrorregião oeste. Os sujeitos voltaram para os seus municípios, visivelmente motivados para a realização das ações, assim como para a continuidade dos debates acerca dos movimentos de EPS.

O que se espera, todavia, é que profissionais, estudantes, docentes, pesquisadores, gestores do ensino e do serviço, e comunidade, ao formularem pactos e políticas visando à EPS, sejam capazes de constituírem-se como redes sociais, traduzidas como prismas nessa região, comprometendose com o desenvolvimento do território e com atenção às coletividades, sobretudo, com a promoção da sua saúde.

\section{REFERÊNCIAS}

1. Motta JIJ, Ribeiro ECO, Worzoler MCC, Barreto CMG, Candal S. Educação permanente em saúde. Rede Unida. Olho Mágico. 2002;9(1):67-78.

2. Ministério da Saúde (BR). Portaria GM/MS no 1.996/07, de 20 de agosto de 2007: dispõe sobre as diretrizes para a implementação da Política Nacional de Educação Permanente em Saúde. Brasília: Ministério da Saúde, 2007.

3. Ministério da Saúde (BR). Decreto $\mathrm{n}^{\circ} 7.508$, de 28 de junho de 2011. Regulamenta a Lei no 8.080, de 19 de setembro e 1990, para dispor sobre a organização do Sistema Único de Saúde-SUS, o planejamento da saúde, a assistência à saúde e a articulação interfederativa, e dá outras providências, [Internet] 2011 [acesso em 22 abr 2012]. Disponível: http://www.conasems.org.br/ site/index.php/juridico/leis-e-decretos

4. Mendes EV. Distritos sanitários: processo social de mudanças nas práticas sanitárias para Sistema Único de Saúde. São Paulo: Hucitec; 1993.

5. Ceccim RB, Feuerwerker LMC. O quadrilátero da formação para a área da saúde: ensino, gestão, atenção e controle social. Physis. 2004;14(1):41-65.

6. Ministério da Saúde (BR). Lei $\mathrm{n}^{\circ} 8.142$, de 28 de dezembro de 1990. Dispõe sobre a participação da comunidade na gestão do Sistema Único de Saúde (SUS) e sobre as transferências intergovernamentais de recursos financeiros na área da saúde e dá outras providências. [Internet] 1990 [acesso em 12 set 2012]. Disponível: http://www.planalto.gov.br/ccivil_03/leis/ L8142.htm

7. Vendruscolo C. Integração ensino-serviço: movimentos das instâncias de gestão nos processos de reorientação da formação profissional na saúde [tese]. Florianópolis (SC): Universidade Federal de Santa Catarina; 2014.

8. Tombini LHT. Educação permanente e integração ensino-serviço na perspectiva dos enfermeiros do serviço [dissertação]. Florianópolis (SC): Universidade Federal de Santa Catarina; 2010. 